\title{
A low-level approach to improve programming learning
}

\author{
Francisco J. Gallego-Durán ${ }^{1}$ • Rosana Satorre-Cuerda ${ }^{1}$ - Patricia \\ Compañ-Rosique $^{1} \cdot$ Carlos Villagrá-Arnedo $^{1} \cdot$ Rafael Molina-Carmona $^{1}$. \\ Faraón Llorens-Largo ${ }^{1}$
}

the date of receipt and acceptance should be inserted later

\begin{abstract}
Learning to program is becoming an universally desired ability. Discovering better ways to teach programming and improving existing ones is essential to increase its accessibility. Presently, most teaching approaches focus on high-level languages and constructs to ease understanding. However, understanding problems seem to persist making the learning process slow and painful. Moreover, mental models developed by students present gaps and misunderstandings that limit their maximum achievable abilities. This paper presents a new approach to teach students bottom-up, starting from machine code and assembler programming. This approach has been tested on first-year university students in two consecutive years. Experimental groups attended a sixteen hours course the week before their first term at the university. Then their performance was comparatively measured against the control group through their marks on the introductory Programming 1 subject. Several potential confounding factors were
\end{abstract}

凶Francisco J. Gallego-Durán

Tel: +34965903400 (Ext. 2073)

Fax: +34965903902

E-mail: fjgallego@ua.es

Rosana Satorre-Cuerda

E-mail: rosana.satorre@ua.es

Patricia Compañ-Rosique

E-mail: patricia.company@ua.es

Carlos Villagrá-Arnedo

E-mail: villagra@ua.es

Rafael Molina-Carmona

E-mail: rmolina@ua.es

Faraón Llorens-Largo

E-mail: faraon.llorens@ua.es

${ }^{1}$ Smart Learning Group

Cátedra Santander-UA de Transformación Digital

Universidad de Alicante

San Vicente del Raspeig, Alicante, Spain also considered. Results suggested that such a small intervention could have positive, tough limited, influence in their programming abilities. Experimental setup is detailed and all data gathered are included for reproducibility.

Keywords Learning to program - Teaching programming · Universal education access · Computational abilities

\section{Introduction}

Computer programming is an increasingly demanded ability. Some practitioners even consider a future in which digital illiterates would be those not knowing how to program computers. In fact, computer programming is far from being a universally accessible ability. Learning to program takes a considerable amount of time and effort, and often requires previous abilities like abstract thinking.

There are many ongoing efforts to help learners to acquire computer programming abilities. In fact, the whole new theme of Computational Thinking arises from this perspective. It is an effort to early teach students required computer programming abilities in a multidisciplinar, transferable way. This is recognizing the growing importance of these abilities, and also the need for properly teaching them.

On past decades, teaching computer programming has mostly been performed at universities. The teaching model has evolved along with the evolution of computing itself. At first, Modula-2, C and Pascal were the preferred languages for teaching. Although low-level and assembly programming were also used and valued, there was an increasing debate against using them for 
teaching. The main arguments against were their difficulty and the lack of student motivation for learning them. These arguments expanded and were also used against Modula-2, C and Pascal, as they became comparatively low-level with respect to new languages like Java, Javascript, Python or Scratch[2, 32]. The general belief is that later languages are easier to learn because they are closer to human language and let the user express intent rather than operations. This general belief is expressed in Association for Computing Machinery's (ACM) Computing Curricula [25]:

\section{The learning outcomes in the Body of Knowledge emphasize higher-level design concepts and interactions between hardware and software [...] the primary focus of the discipline is on their use in designing systems to meet specified needs. [...]}

The ACM expresses here that Computer Engineers shall focus on higher-level design concepts rather than on machine level operations. This does not exclude them from learning low-level concepts, but the clear focus expressed on higher-level concepts has been translated into the usage of higher-level languages from the start. As this view is applied to Computer Engineers, teaching computer programming on high-schools or dedicated courses has greater focus on high-level concepts and languages.

However, to the best of our knowledge, there is no proof that higher-level languages improve the process of learning to program. In fact, their higher productivity might be hiding the actual learning process. Students may be able to produce working code without properly understanding the underlying computing process. It is reasonable to assume that languages that hide the computing process prevent students from analysing and comprehending it.

This work started by considering the constructivist point of view of learning. By this view, a proper understanding of computers and programming should be built bottom-up: understanding how a computer processes information, talking directly to it, mastering how it works, then continue moving upwards until reaching higher-level languages for productivity. This approach seems rational from the learning point of view, but has been progressively abandoned because of the difficulty in teaching low-level programming. Therefore, our previous work addressed this difficulty issue. Our results showed that there is no intrinsic difficulty to either machine code or assembly, suggesting that the problem is probably due to the way contents are being taught.

To obtain previous results we created a complete blended-learning course on machine code and assembly language, called Dominando Ensamblador del Z80
(DEZ80, Mastering Z80 assembly in English). It was administered to first-year undergraduate students before their first term at the university. Present study starts questioning whether the course had a mediumlong term impact on attending students. Specifically, it is focused on the impact of DEZ80 on first-year main programming subject Programming 1.

Section 2 starts by considering related previous studies and their conclusions. Then section 3 sumarizes the details about the DEZ80 course. Specific research questions for this study are considered in section 4, including DEZ80 specific conditions and also confunding factors. All organizing and data gathering details are described in section 5 to ensure replicability of these results. Data analyses is shown in section 6 along with a discussion on their significance. Finally, section 7 summarizes conclusions and further research to be considered.

\section{Background}

Programming is considered a core component of science and engineering disciplines related to computing $[2,25]$. It is also the core component of Computational Thinking [1, 9, 29, 46]. Aho's definition of Computational Thinking states it clearly "thought processes involved in formulating problems so their solutions can be represented as computational steps and algorithms" [1]. Many countries are showing a growing interest in teaching Computational Thinking as a way to transmit involved problem-solving skills to their population $[18,31]$. In this sense, Denning and Tendre [9] state that Computational Thinking involves two main mental skills: (a) designing computations that get computers to do jobs for us and (b) explaining and interpreting the world as a complex of information processes.

Computational Thinking emerges from the observation of the abilities that computer engineers show with respect to problem solving and information managing. Most authors agree in that these abilities are a probable consequence of computer programming practice. However, many Computational Thinking advocates try to avoid programming as the way to get these abilities. This is contradictory with mental skill (a) [9], which is a description of what computer programming is, and generally requires learning how computers work up to a certain level of understanding. This escape from programming seems to be related to the common belief that learning to program is difficult $[4,15,21,22,27$, $28,32,34,36,40,41,47]$. This is probably the main obstacle for universal access to programming and Computational Thinking: there is no known way to efficiently learn to program. Let us understand efficient learning 
as acquiring sound abilities without requiring higherthan-normal motivation, effort or previous abilities.

From a constructivist point of view ${ }^{1}$, learning to program requires understanding of computers and then structuring knowledge to solve problems by programming computers $[5,6,8,11,16,24,26,35]$. So, it seems reasonable to start by learning details close to the machine, to develop a proper understanding of it, then progressively move to more productive languages. Although being reasonable, this point of view is almost absent in the literature [32], specially in most recent works, to the best of our knowledge $[2,10,12,19,20$, $21,40,42,43]$. In fact, many teachers that had to teach some form of assembly language declare it to be intrinsically hard and advocate in favor of higher level languages [3, 21, 42, 45]. Many high-level languages have even been designed with novices in mind, but expectations have generally not been meet, as [27] indicates: "Many general-purpose languages have been influenced by [...] a desire to make the programming language easier to implement, making the resulting languages unnecessarily difficult for beginning programmers".

With respect to teaching programming, there is a global tendency towards using higher and higher level languages. This tendency seems to be related to learning to program being considered inherently difficult $[7$, $10,19,28,30,37]$. This consideration is mainly based on teachers' experience [28] and usually justified on it requiring many high-level thinking abilities like logical thinking, abstraction, problem-solving, etc. In fact, failure rates in introductory programming have been a general concern in past decades [4]. There also seems to be a common impression that programming in higher-level languages is easier and conceptually clearer, because these languages are more similar to human languages.

As learners start their journey with high level languages, two questions raise: are they properly learning to program? and, are they obtaining the same mental abilities that Computational Thinking pursues? These questions started our previous work [14], driving us to explore two points of view: can a bottom-up teaching approach improve learning results? and, is this approach actually valid in terms of starting difficulty? First question raises from classroom experience with students' programming abilities. This questioning made us seriously analyse third and fourth year students' developed mental models on problem solving and programming [13, 16, 17, 24, 33]. The conclusion was that students had developed erroneous mental models and

1 This work understands constructivism in its usual educative conception: new knowledge is built on top of previous knowledge. Each piece of knowledge learnt should support following knowledge, in a bottom-up fashion[44]. that made them less able to design proper programming solutions to problems. Moreover, the more lowlevel knowledge students were asked for, the more inaccurate their mental models were. As high level languages hide details on how the machine works, it is reasonable to believe that students do not acquire a competent understanding on how exactly their programs are being executed. This may be the reason why their mental and conceptual models are erroneous, and that could be compromising their problem-solving, programming and ultimately Computational Thinking abilities $[16,17,24,33]$.

Therefore, our initial study suggested us that students were not properly learning to program because of their erroneous understanding of the execution model of the machine. It also suggested us that a constructivist approach to the problem could be a valid start to tackle these issues. However reasonable, there still was the second question as an obstacle for the bottom-up knowledge approach. If machine code and assembly languages were intrinsically difficult, using them as a starting point to teach may not be appropriate. Therefore, we continued our work testing this difficulty hypothesis with a counterexample approach. In [14] we created the DEZ80 machine code and assembly language course with a modern, gamified design $[10,19,23,38,39,40$, 48]. The idea was to test if the teaching approach could mitigate the difficulty perception on students. Study was conducted in a blended-learning fashion, with firstyear university students, one week before the start of their first term. Results showed that they enjoyed learning machine code and assembly languages and their perception of difficulty was even lower than expected. Even the final, most difficult parts of the course were marked with less than 3.5 points on a $[1-5]$ range (Marks 3 to 5 were labeled normal, difficult and very difficult). These results strongly suggested that difficulty of machine code and assembly languages came from the way in which they are taught more than from an intrinsic nature.

All this previous work suggested that a constructivist approach is feasible and potentially beneficial. This could help students to develop proper mental and conceptual models on how the machine works. Properly acquiring these models could foster computational thinking abilities. Present study goes one step forward by performing a first follow-up analysis of the students that participated in the machine code and assembly course. Their results in Programming subjects is considered and compared to other students that did not attend the course. 


\section{Mastering Z80 assembly course (DEZ80)}

Mastering Z80 Assembler ${ }^{2}$ is a course created to introduce students into programming, starting from machine code and Z80 assembler. It was created in 2016 as counterexample for the general belief that assembler has a high intrinsic difficulty that prevents students from learning it [14]. DEZ80 is composed of 52 video lessons classified in three levels. Figure 1 shows an example screenshot of the video in which pixel color format is explained. First and second levels cover machine code language, and the third introduces to assembler programming. All the course is designed around game development activities proposed as challenges, as a way to motivate students. Challenges are the central driver of the course, encouraging learners to try different ways to solve them. Theoretical knowledge has a secondary role, assisting learners in finding ways to solve their challenges.

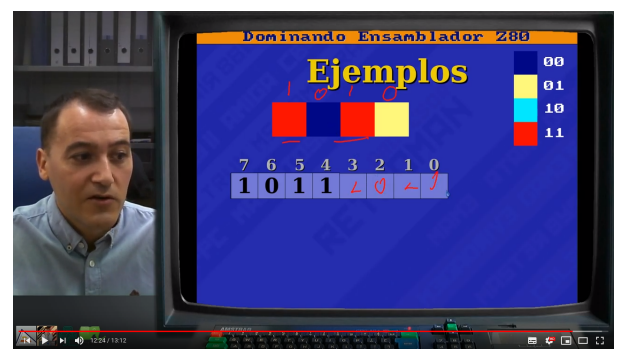

Fig. 1 An example video of DEZ80: explaining how pixels and colours are codified in Amstrad CPC's video memory.

The design of the course targets the Z80 processor because it is one of the simplest ancestors of modern Intel processors. Simplicity is important for starting students: modern processors have thousands of instructions, operation modes, addressing modes and caveats. Therefore, a classic 8-bits processor as the Z80 is a reasonable starting point to easily understand machine code and assembly. Moreover, it has the advantage of having being used on many machines, with advanced emulators available. In turn, emulators have the advantage of including advanced debuggers. For DEZ80, the Amstrad CPC emulator WinAPE 2.0b2 ${ }^{3}$ was used (figure 2). WinAPE includes editor, assembler, and a complete debugger of the Amstrad CPC. This is a complete

2 Complete course available at http://dez80.byterealms. com, alternatively at https://web.archive.org/web/ 20200121110806/http://dez80.byterealms.com/. Content in Spanish only. Last accessed: 2020/01/28

3 Available at https://web.archive.org/web/ 20191231172443/http://www.winape.net/downloads.jsp. Last accessed: 2020/01/28. set of tools to teach, learn, program and debug from the start.

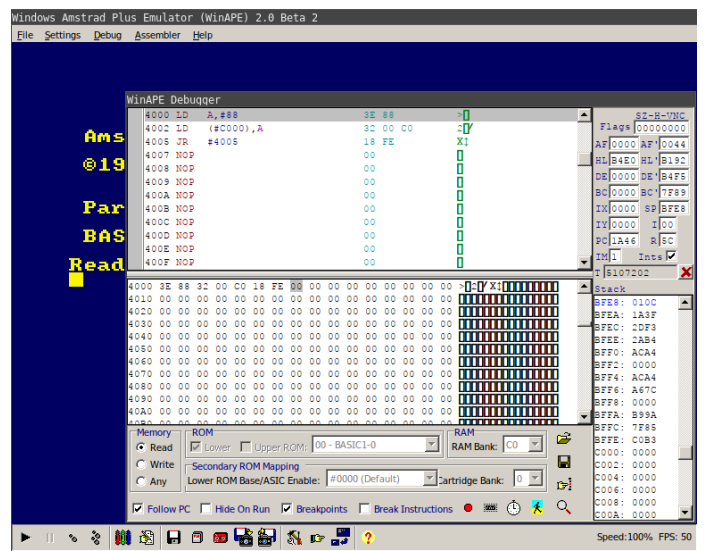

Fig. 2 WinAPE 2.0 beta 2 emulator. On forefront, debugger window including disassembly, editable memory dump, processor, stack, configuration and utilities. Behind, an Amstrad CPC being emulated (emulation stopped for debugging).

DEZ80 contents outline is as follows:

- Level 0. videos: 4. Introductory explanations on course contents and philosophy.

- Level 1. videos: 14 practical, 7 theoretical. Challenges: 5. Starts from scratch. Goal: drawing of a custom sprite (a 16x16 pixels image). Contents: execution model, instructions, sequential execution, CPU registers and memory, loading data, binary and hexadecimal, video memory, pixel format, drawing pixels.

- Level 2. videos: 9 practical, 5 theoretical. Challenges: 5. Goal: programming a complete animation. Contents: time control and interrupts, raster scan, positive and negative numbers, repetitions and loops, memory storage and variables, animations.

- Level 3. videos: 11 practical, 2 theoretical. Challenges: 5. Goal: programming first simple game. Contents: introduction to assembler, keyboard input, conditionals, functions, program stack, game loop.

This study considers DEZ80 course as an intervention experiment. On years 2017/2018 and 2018/2019 a portion of the students attended in-person and confronted DEZ80 challenges individually. Students could have done activities remotely, but on-site practice let them help each other, work in groups and ask teachers for help. Moreover, on-site group learning promoted a positive atmosphere that encouraged students. Onsite lessons were held the week before term started, Monday to Friday, 16:00h to 20:00h, totaling twenty hours. These hours included course presentation (1.5 hours) and a group activity in the assembly hall the 
last day (2.5 hours). That left approximately 16 hours to complete all course challenges. This is an optimal approximate value, because it does not take into account breaks. A more realistic upper boundary would be approximately 12-14 hours.

These students entered either the Computer Engineering Degree or the Multimedia Engineering Degree immediately afterwards. Many other students also entered these degrees without having attended DEZ80 course. Therefore, present study considers those attending DEZ80 course as the Experimental Group (EGr) and those not attending as the Control Group (CGr). In order to analyse potential differences between both groups, and potential factors producing those differences, first we start by considering the research questions that will be analysed.

\section{Research questions}

In order to analyse the impact of the DEZ80 course on students that attended it, we considered a series of research questions to analyse. These questions had two main purposes: identify differences in performance between experimental and control groups with respect to the subject Programming 1, and determine the influence of confounding factors and biases in this difference.

Our research questions where:

1. Are Programming 1 marks influenced by DEZ80 attendance?

2. Does performance in DEZ80 predict performance in Programming 1?

3. Confounding factors:

(a) Does students' self-reported previous programming experience influence marks on Programming 1 ?

(b) Is there any difference between self-learners and those that learned in academic environments?

(c) Does students' self-reported likeness of programming predict marks on Programming 1?

For these questions we considered students depending on the degree they entered (Computer Engineering or Multimedia Engineering) and the year they entered (2017/2018 or $2018 / 2019)$.

\section{Experimental setup}

To answer our research questions we used DEZ80 course as an experimental intervention on first year students. Selected students formed the experimental group (EGr) and participated in the DEZ80 course before starting their first term at the university. The control group (CGr) was formed from the non-selected students.

Both groups started their first term at the university the week after DEZ80 course. This study measures performance results of EGr students in the DEZ80 course along with their answers to pre/post-course surveys. It also measures performance of EGr and CGr students in the subject Programming 1. This subject introduces students to programming in $\mathrm{C}$ from scratch, assuming no previous knowledge. The subject has three major milestones to measure student performance: two intermediate practical programming exams and one final theoretical/practical exam.

These are all the sequential steps that conformed the time-line for our experimental setup:

1. Selection of first-year students for the experimental group

2. (EGr) Survey on previous knowledge

3. (EGr) 1-week DEZ80 course

4. (EGr) Post-course survey

5. (EGr, CGr) Start of term: Programming 1 starts.

6. (EGr, CGr) 1st practical exam.

7. (EGr, CGr) 2nd practical exam.

8. (EGr, CGr) Final exam.

In the results section we analyse the influence of the DEZ80 course intervention in the programming performance measured by Programming 1 milestones. With such results we discuss plausible answers to our research questions.

In order for our experiments to be reproducible, next we detail all the design and contents of each one of the steps in our experimental setup.

\subsection{Selection of students for DEZ80 course}

The most appropriate way to select students for DEZ80 course would have been a random sample from new year students. However, this was impossible. The course could not be proposed as mandatory, and so it was voluntary. This is better for students, as they are keen to attend and participate, but it introduces a bias that has to be taken into account. Attendees are expected to have the common will to assist and participate, which is not expected to be the common will for all entering new students.

All new-entering students were invited to sign in for DEZ80, but only a random sample was picked from those who signed in. This was done in order to mitigate as much as possible the bias towards highly motivated attendees. Also, students were told the course was special and relevant for their careers, and so they perceived it as something valuable and interesting. The 
intention was to motivate most students to sign in, having a less biased sample. These measures were a minor palliative to the inevitable bias, but were the best possible alternative we thought of fitting the organizing circumstances. Therefore, results of this study have to be considered with motivated attendees bias in mind.

Future experiments having the opportunity to remove this bias would be necessary to clearly characterize its influence and get more general results.

\subsection{Pre/post DEZ80 surveys}

Before starting DEZ80 course, we conducted an initial survey $^{4}$ to know previous knowledge and expectations of selected students. It mainly consisted of the following six questions:

1. Do you have previous knowledge on computer programming? (yes/no)

2. How did you acquire your programming knowledge? (selftaught, highschool lessons, specific academic programming courses, other)

3. Which programming languages do you know? (Java, Javascript, Scratch, $\mathrm{C} / \mathrm{C}++$, Assembler, other)

4. For how many years have you been programming? (free answer)

5. How much do you say you enjoy programming? (010)

6. Which kind of programs would you like to do? (Computer games, operative systems, graphical applications, robotics, management applications, other)

These introductory questions let us have a broad picture of the attendants to the course. Moreover, this also helps differentiating the actual influence of the course on the EGr from some confounding factors related to previous experience. For instance, students with previous knowledge and programming experience are expected to perform better than those starting from scratch. This information is analysed in the results section.

On the last day of DEZ80 we also conducted another survey to know student perception on the course. This survey consisted of :

1. How many days did you attend the course (1-5)

2. How many hours did you invest outside classroom? (0, 1-3, 3-6, 6-10, more than 10)

3. Which is the highest level you achieved? (1-3)

4. Check the concepts you consider to have learnt (checklist with 32 programming concepts involved in the challenges)

4 Original surveys are available at http://hdl.handle.net/ 10045/73430 in Spanish. Last accessed 2020/01/28.
5. How difficult have you found the challenges? (5valued likert scale for each one of the 15 DEZ80 challenges)

6. Tell us what other things you would like to continue learning (yes/no for these 8 items: machine code, assembler, graphics, computer technical internals, Amstrad CPC, computers and consoles, computer game programming, languages and compilers)

7. Write your personal views on level (3 open questions, one for each level 1-3)

8. What is your overall opinion on the course? Would you recommend it? (open question, yes/no)

The main ideas are to know the perceived difficulty of the challenges, its relation to the time invested, along with student opinion on the course in general.

\subsection{Programming 1: term and exams}

All students from both EGr and CGr groups entered their degrees and studied Programming 1. This subject introduced students to C-language programming from scratch. Main topics were:

1. Basic Data types.

2. Sequential instruction execution.

3. Control flow: conditionals and loops.

4. Modularization: functions and parameters.

5. Structured data types: registers and arrays.

6. Recursion.

7. Code complexity and costs.

The subject emphasized design and problem solving abilities as well as code correctness and safe programming style. Students were required to pass two practical exams and one theoretical. Practicals were solved in a computer with editor and compiler, theoretical required pen and paper only.

First practical was held in the ninth week and included topics 1 to 4 . Students were required to create a program that showed they master basic data types and control flow. They were also required to create functions and pass parameters, but module design was given. Assessment was based on their code working and their programming style being correct.

Second practical was held during fifteenth week. Students were required to program using arrays of registers, inserting, modifying and deleting values, and also performing iterative and recursive calculations on them. A proper modular design by their own was also mandatory. Assessment is similar to first practical, but covering all topics except code complexity.

The theoretical exam was held four weeks after the second practical, at the end of the term. With almost 
same contents as the second practical, it tested students in a different way. Without editor and compiler, they lost the trial-and-error way, and so they were required to show higher level understanding, design abilities and problem solving. Assessment focused on these high-order thinking abilities and mastery of concepts, not penalizing syntactical issues in the code.

Final marks obtained by students were 15 points for the first practical, 35 for the second and 35 for the theoretical. Another 15 points were given for classroom exercises. In order to pass the subject, it was mandatory to obtain at least 14 points out of $35(40 \%)$ in the second practical and also in the theoretical exams. There was no minimum requisite for the first practical.

\subsection{Selection of relevant data for study}

Before analysing student performance with respect to their preconditions, we performed a selection of relevant data for comparisons. As the most important point is to compare student performance results with their preconditions, our first logical step was removing all students that abandoned without doing Programming 1 exams. This was done because there is no way to compare data from preconditions with an absence of information on performance. For this same reason, only those students that performed at least second practical and theoretical exams have been considered. This condition affects both EGr and CGr, although proportions are different.

Second practical and theoretical exams have been selected as threshold point because both of them had a minimum requisite of $40 \%$ to pass Programming 1 . Students not attending any of these two exams can safely be considered to have abandoned the subject. In these cases, their final result is undefined and cannot be related to understand performance influence of DEZ80 over Programming 1. Moreover, as there are many potential reasons for first-year students to abandon the subject, data from these students may have introduced many uncontrolled biases.

As DEZ80 course was only offered to entering firstyear students, only these students were considered both for EGr and CGr. Therefore, students that entered their degrees previously to $2017 / 2018$ and were repeating Programming 1 were removed. Moreover, students that entered 2017/2018 and repeated Programming 1 next year were also removed from 2018/2019 data (they were only considered on $2017 / 2018$ ). This ensures that students are compared in fair conditions. Repeating students have had programming lessons at the University, and that would bias results from the CGr.

After selection, students have been classified by their degree and their year. Although the subject Program- ming 1 is common to both Computer Engineering and Multimedia Engineering degrees, students are considered to select their degree depending on their personal profile. Teachers believe students from Multimedia Engineering to be more creative and those from Computer Engineering to be more technical. Teachers report the perception of these differences on higher years. However, to account for these potentially different student profiles, we consider both groups separately. Please note that these two groups are independent from our already defined EGr and CGr, and students from both degrees are mixed amongst them.

As will be shown in the section 6 , some of the attendees to DEZ80 (EGr) either did not solve any challenge or did not submit their solutions. Therefore, only those that solved and submitted at least one DEZ80 challenge are considered. This ensures that EGr students considered have at least actively participated on DEZ80. Otherwise, it could not be safe to consider any effect of DEZ80 course on students, as some of them may not have actively participated.

\section{Results}

This section shows data analyses about our research questions, empirical results and their discussion. Raw data used for these analyses, conveniently anonymised, is publicly available at the institutional repository of the University of Alicante (RUA) ${ }^{5}$. Data comprises firstyear students from Computer Engineering (CE) and Multimedia Engineering Degrees (ME) at the University of Alicante from the academic years 2017/2018 and 2018/2019 ( named 2017 and 2018 for short). This database only considers entering first-year students: repeating students have been already removed. Table 1 sums up the general information on both samples.

Table 1 DEZ80 EGr Selected and attending students. ([St]udents in total, CE: Computer Engineering, M: Multimedia Engineering, [Ap]plicants to DEZ80, [Se]lected for DEZ80, [At]tendees, Cp: Completed 1 or more DEZ80 challenges, P1: did all Programming 1 exams)

\begin{tabular}{|l|r|r|r|r|r|r|r|r|}
\hline Term & St & CE & ME & Ap & Se & At & Cp & P1 \\
\hline \hline 2017 & 398 & 287 & 111 & 140 & 107 & 95 & 69 & 54 \\
2018 & 434 & 315 & 119 & 135 & 75 & 72 & 67 & 55 \\
\hline \hline Total & 833 & 603 & 230 & 275 & 182 & 167 & 136 & 109 \\
\hline
\end{tabular}

As table 1 shows, the global sample for this study includes 833 students, 398 from 2017 and 434 from 2018.

5 Raw Database from 2017-2019 students and attendees to DEZ80 course. Last accessed 03/02/2020. http://rua.ua.es/ dspace/handle/10045/102169 
Both years include students from Computer Engineering (CE) and Multimedia Engineering (ME) degrees, which are considered separately in our analyses. Next columns show how the sample is shrank as different criteria are applied. First, students who applied (Ap) for the DEZ80 course, and those who were selected (Se). The number of students selected on 2018 is $25 \%$ less than 2017 because of space constraints in assigned classrooms. Most selected students attended (At) and similar number were verified to complete one or more challenges $(\mathrm{Cp})$ of the DEZ80 course. Approximately $80 \%$ of these students also did all three Programming 1 exams.

\subsection{Q1: Influence of DEZ80 on Programming 1}

In order to know if participating in the DEZ80 course influenced Programming 1 marks, we conducted a series of ANOVA analyses. Students from each year and degree are considered into two groups: DEZ80 attendees (Z) and students that did not attend DEZ80 (no). Table 2 shows resulting p-values for all ANOVA analyses performed.

Table 2 ANOVA p-values with $95 \%$ confidence interval to test null-hypothesis on the influence that attending DEZ80 course has on Programming 1 marks. Students are considered by year (2017 or 2018) and by degree (Computer Engineering, $\mathrm{CE}$ or Multimedia Engineering, ME). Tests are performed against marks obtained in each of the 3 Programming 1 exams ([Pr]actice-1 \& 2, and [The]ory) and against final marks (P1). $\left[N_{z}\right]$ : students attending DEZ80, $\left[N_{n o}\right]$ : students not attending DEZ80.

\begin{tabular}{|l|r|r|r|r|r|r|}
\hline Group & $N_{Z}$ & $N_{n o}$ & Pr-1 & Pr-2 & The & P1 \\
\hline \hline 2017-CE & 34 & 187 & $\underline{0.057}$ & 0.113 & $\mathbf{0 . 0 2 5}$ & $\mathbf{0 . 0 1 2}$ \\
2017-ME & 20 & 75 & 0.331 & 0.421 & 0.232 & 0.216 \\
2018-CE & 33 & 180 & $\underline{0.065}$ & 0.253 & 0.270 & 0.692 \\
2018-ME & 22 & 70 & 0.264 & 0.092 & $\underline{0.051}$ & $\mathbf{0 . 0 4 0}$ \\
\hline
\end{tabular}

ANOVA analyses yielded difficult to interpret results. The three cases shown in bold in table 2 are those in which the null-hypothesis (DEZ80 does not influence Programming 1 marks) can be discarded. There are also three more cases underlined in table 2 whose pvalue is so close to 0.05 than they should be considered as potentially significant. These means that attending DEZ80 course and solving one or more challenges could have had an impact on 2017-CE and 2018-ME students. In both cases, the impact is related to the theory exam and final marks. However, this contrasts greatly with 2017-ME and 2018-CE students whose theory and final marks seem to have no relation at all with their attendance to DEZ80.
The interesting part of these results is that DEZ80 course was not designed to be aligned with Programming 1 contents. Moreover, it is a very short and optional course, meaning that students are not expected to develop significant abilities. Therefore, no relation at all should be expected between DEZ80 and Programming 1 marks. However, highlighted p-values seem to be indicating a potential relation. A potential explanation would be that the actual influence is small but measurable. That could explain why 2 out of 4 groups show it as significant, whereas the other 2 do not: if the influence is small, noisy factors could easily make it insignificant.

For instance, let us consider this influence with a deeper perspective. Figures 3 and 4 show the average final marks students achieved depending on the number of total DEZ80 challenges they solved. Both figures highlight as a continuous line the group that shows a significant influence of DEZ80 over Programming 1 final marks. Both cases, 2017-CE and 2018-ME, show no apparent difference in final marks depending on how many challenges students solved. Both might have been uniform groups with respect to student abilities or learning outcomes. These could explain why participation on DEZ80 directly influenced final marks as a significant factor.

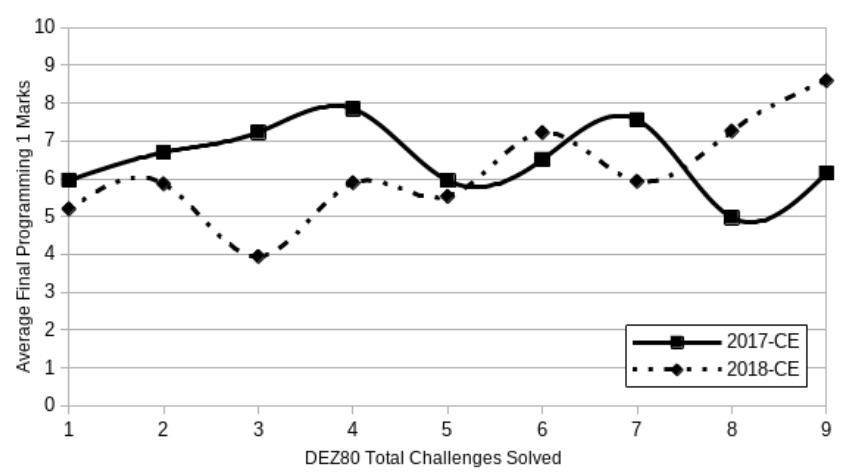

Fig. 3 Average marks of Computer Engineering students depending on DEZ80 challenges solved.

On the contrary, groups 2018-CE and 2017-ME show a tendency to higher marks for those students that solved more challenges (with some outliers). This support the previous reasoning, because in these cases the fact that a student attended DEZ80 does not explain final marks by itself: it has to be complemented with the total number of challenges solved. This also supports the idea that DEZ80 could have some influence in final Programming 1 marks, but this influence might be related to several factors: not only attending, but also solving many challenges. It is also possible that some challenges were more important than others, or 
their learning outcome to be different depending on how they were solved, but that goes beyond the scope of this study.

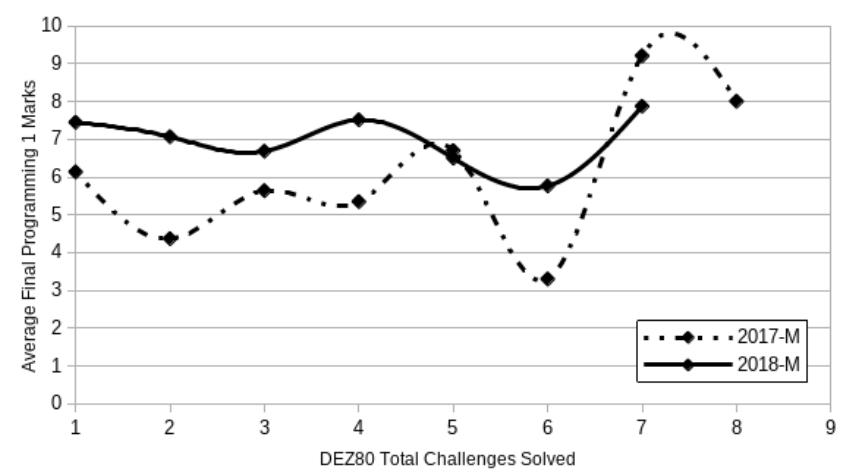

Fig. 4 Average marks of Multimedia Engineering students depending on DEZ80 challenges solved.

\subsection{Q2: Performance relation between DEZ80 and Programing 1}

Figures 3 and 4 partially answer the second research question. Similar to Q1, it appears to be a weak relation between the number of DEZ80 challenges solved (performance) and Programming 1 final marks. To analyse this relation more clearly, table 3 shows calculated Pearson's coefficients for all related performance values.

Table 3 Pearson coefficients between DEZ80 total number of challenges solved and Programming 1 marks. Students are considered by year (2017 or 2018) and by degree (Computer Engineering, CE or Multimedia Engineering, ME). Tests are performed against marks obtained in each of the 3 Programming 1 exams ([Pr]actice-1 \& 2, and [The]ory) and against final marks $(\mathrm{P} 1)$. $\left[N_{z}\right]$ : students attending DEZ80.

\begin{tabular}{|l|r|r|r|r|r|}
\hline Group & $N_{Z}$ & Pr-1 & Pr-2 & The & P1 \\
\hline \hline 2017-CE & 34 & 0.052 & -0.017 & -0.010 & -0.039 \\
2017-ME & 20 & $\underline{0.335}$ & 0.283 & $\mathbf{0 . 4 8 2}$ & $\underline{0.380}$ \\
2018-CE & 33 & 0.283 & 0.156 & $\underline{0.344}$ & $\underline{0.330}$ \\
2018-ME & 22 & 0.114 & -0.026 & $\underline{-0.363}$ & -0.121 \\
\hline
\end{tabular}

Pearson coefficients from table 3 approximately confirm our intuition from figures 3 and 4 . It shows a positive linear correlation (in bold) between DEZ80 challenges and theory exam marks from 2017-ME group that rejects the null-hypothesis $(\mathrm{p}$-value $=0.031)$. It also shows other potential relations (underlined) that do not reject the null-hypothesis but are close ( $\mathrm{p}$-values $<0.10)$. Even if their statistical significance is weak, they show a relevant tendency in favor of previously discussed explanations. This could be more relevant con- sidering the small size of the sample for these groups, and the great influence of outlier points. This is apparent in figure 4: the 2017-ME group is similar in all the points to 2018-CE from figure 3, except for the marks related to 6 challenges solved. This point appears to be an outlier due to the size of the sample.

These results do not represent enough evidence to establish a relation between DEZ80 performance and Programming 1 performance. However, taking into account the factors previously discussed and the small size of the sample, the existence of a small influence cannot be discarded. Also, the possibility of a influence based on a combination of factors, including performance, is also possible. In any case, further evidence is required to better diagnose and form a solid conclusion.

\subsection{Q3.a: Previous programming experience}

The first of the confounding factors considered is students' previous programming experience. It is reasonable for students which have been previously exposed to programming to get better marks on Programming 1. The influence of their previous knowledge could be much greater than the influence of what they learned in DEZ80 course. To take this into account our pre-survey asked them to report their previous programming experience.

First test (table 4) uses ANOVA to establish statistical significance on this influence on each one of the Programming 1 marks (Practical exams 1\&2, theoretical and final marks). Results show that there is almost no possibility at all to discard the null-hypothesis (no influence of self-reported previous programming experience). There are only three values below 0.1 and only one of them close enough to be considered (0.062) but, as other related values are very high, these values seem nothing more than statistical variance.

Table 4 ANOVA p-values with $95 \%$ confidence interval to test null-hypothesis on the influence of self-reported previous programming experience on Programming 1 marks. Students are considered by year (2017 or 2018) and by degree (Computer Engineering, CE or Multimedia Engineering, $\mathrm{ME})$. Tests are performed against marks obtained in each of the 3 Programming 1 exams ([Pr]actice- $1 \& 2$, and [The]ory) and against final marks $(\mathrm{P} 1) .\left[N_{e}\right]$ : students that reported previous experience, $\left[N_{b}\right]$ : students not reporting previous experience.

\begin{tabular}{|l|r|r|r|r|r|r|}
\hline Group & $N_{e}$ & $N_{n}$ & Pr-1 & Pr-2 & The & P1 \\
\hline \hline 2017-CE & 18 & 16 & 0.996 & 0.519 & 0.608 & 0.610 \\
2017-ME & 6 & 14 & 0.470 & $\underline{0.062}$ & 0.330 & 0.253 \\
2018-CE & 19 & 14 & 0.240 & $\underline{0.091}$ & 0.325 & $\underline{0.084}$ \\
2018-ME & 13 & 9 & 0.495 & 0.384 & 0.269 & 0.562 \\
\hline
\end{tabular}


Finding no statistical relation between previous programming experience and Programming 1 marks is contrary to expectations. This could be due to what students may have considered as "previous experience": they might think that some hours playing around or a few introductory lessons could be considered previous experience. As evidence is self-reported, many subjective consideration factors could add noise to this data. That might explain why such a logical relation does not show in these experiments.

Another explanation might be that previous experience relation only arises when some threshold is surpassed. For that possibility, our survey also asked students for how long had they already been programming. Using this data, table 5 shows Pearson's correlation coefficients between self-reported previous years of programming experience and different marks obtained in Programming 1.

Table 5 results are unexpected again, as there seems to be no strong correlations with most of the groups and marks with respect to self-reported previous years of programming experience. Interestingly, 2018-CE is the only group that shows statistically significant correlations for theoretical exam and final marks ( $\mathrm{p}$-values: 0.042 and 0.031 respectively). This group was one of the two not showing statistical significance for the influence of DEZ80 on Programming 1 marks (see table 2), and these results might explain why. It is reasonable to deduce that the influence of this group participating in DEZ80 is much smaller than the effect of previous programming knowledge. This confounding factor might have played an important role and shadowed the influence of DEZ80 in 2018-CE group. The influence of this confounding factor is better appreciated in figure 5 .

Table 5 Pearson coefficients between self-reported previous years of programming experience and Programming 1 marks. Students are considered by year (2017 or 2018) and by degree (Computer Engineering, CE or Multimedia Engineering, ME). Tests are performed against marks obtained in each of the 3 Programming 1 exams ([Pr]actice-1 \& 2, and [The]ory) and against final marks (P1). $[N]$ : students meeting criteria.

\begin{tabular}{|l|r|r|r|r|r|}
\hline Group & $N$ & Pr-1 & Pr-2 & The & P1 \\
\hline \hline 2017-CE & 14 & 0,121 & 0,246 & $-0,243$ & $-0,091$ \\
2017-ME & 6 & 0,234 & 0,012 & 0,334 & 0,228 \\
2018-CE & 19 & 0,258 & 0,233 & $\mathbf{0 , 3 1 9}$ & $\mathbf{0 , 3 3 7}$ \\
2018-ME & 13 & 0,397 & $-0,133$ & 0,191 & 0,084 \\
\hline
\end{tabular}

Another interesting conclusion drawn from table 5 and figure 5 is that the null-hypothesis cannot be discarded for the rest of the groups (2017-CE, 2017-ME, 2018-ME) and so it can be assumed that previous experience in general did not act as confounding factor in these three cases. This strengthens support for the influence of DEZ80 in Programming 1 marks, particularly for groups 2017-CE and 2018-ME which showed statistical significance (see table 2). In fact, both groups showed the weakest signs of correlation between previous experience and both theory and final marks in table 5 .

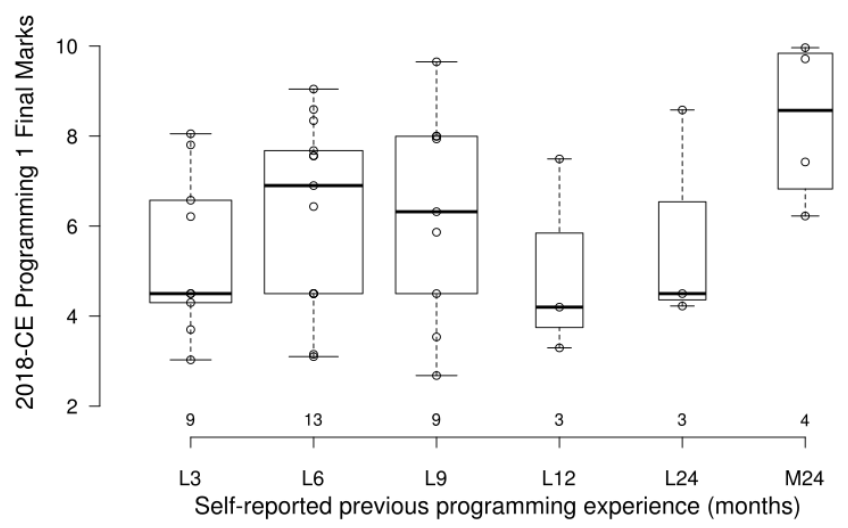

Fig. 5 2018-CE Programming 1 final marks depending on selfreported previous months of programming experience (LX: Less than X, MX: More than X).

\subsection{Q3.b: Self-learners versus academic-only students}

Another possible confounding factor we considered was the influence of students being self-taught versus those only following academic courses. The reason behind this factor is to take into account their willingness to learn. It is reasonable to believe that students become increasingly self-taught as their motivation to learn programming is greater. On the contrary, those following only their high-school subjects or academically regulated environments might have done so as part of their education, or not, but without so much interest. Therefore, all students that attended DEZ80 but did not report being self-taught were considered only academic students.

To test null-hypothesis (self-taught students are not different than academic-learned) we conducted ANOVA analyses between both groups ([N $\left.N_{s}\right]$ : students that reported to be self-taught, $\left[N_{a}\right]$ : academic-only students) and their Programming 1 results on the three exams. Table 6 shows these results.

Interestingly, there is a statistically significant difference between academic-only and self-taught students in the 2017-CE group, with respect to Programming 1 marks. Moreover, other groups do not show any difference between both types of students. This seems to point to a particular situation of the 2017-CE group, which needs to be studied in greater detail. Figure 6 
Table 6 ANOVA p-values with $95 \%$ confidence interval on self-taught students versus academic-only with respect to their influence in Programming 1 marks. Students are considered by year (2017 or 2018) and by degree (Computer Engineering, $\mathrm{CE}$ or Multimedia, M). Tests are performed against marks obtained in each of the 3 Programming 1 exams ([Pr]actice- $1 \& 2$, and [The]ory) and against final marks (P1). $\left[N_{s}\right]$ : self-taught students, $\left[N_{a}\right]$ : academic-only students.

\begin{tabular}{|l|r|r|r|r|r|r|}
\hline Group & $N_{s}$ & $N_{a}$ & Pr-1 & Pr-2 & The & P1 \\
\hline \hline 2017-CE & 14 & 20 & 0.110 & 0.551 & $\mathbf{0 . 0 1 4}$ & $\mathbf{0 . 0 4 4}$ \\
2017-ME & 3 & 17 & 0.424 & 0.128 & 0.745 & 0.302 \\
2018-CE & 5 & 28 & 0.733 & 0.873 & 0.390 & 0.522 \\
2018-ME & 3 & 19 & 0.779 & 0.277 & 0.477 & 0.216 \\
\hline
\end{tabular}

shows a comparison between both student types inside the group 2017-CE with respect to their results in Programming 1.

First deduction from figure 6 is that self-taught students beat academic-only ones in all Programming 1 exams and, consequently, in their final marks. This seems to confirm our initial impression about this confounding factor. These results suggest that 2017-CE group had a positive performance bias in Programming 1 results driven by the 14 self-taught students. As we stated previously, this could be explained by the additional motivation students are expected to have when they invest time in learning by themselves.

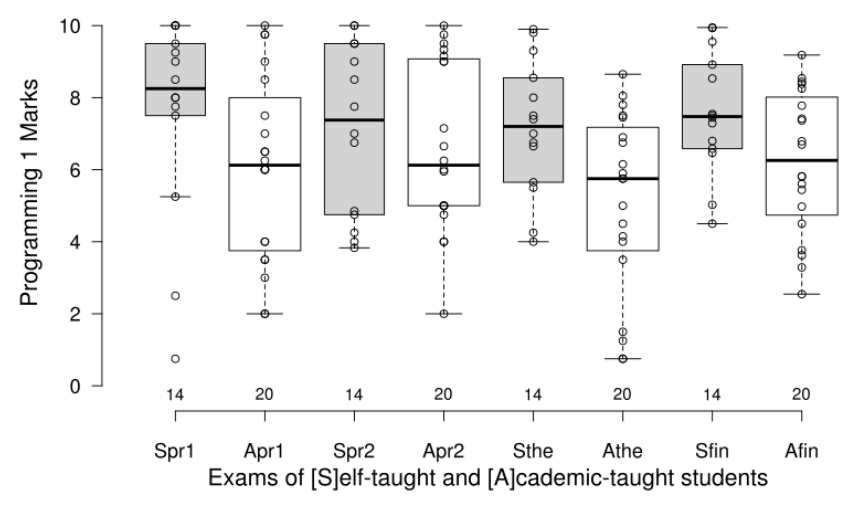

Fig. 6 2017-CE Programming 1 differences in marks between [S]elf-taught students (grey boxes) and [A]cademic-only students (white boxes) for $[\mathrm{Pr}]$ actice $1 \& 2$ and [The]ory exams, and the [fin]al marks.

This result does not support our previous deductions in favor of the influence of DEZ80 on Programming 1 marks for 2017-CE group. In this case, this confounding factor inherent to the students in the group seems to have a great impact in results. In contrast, group 2018-ME that also has shown influence of DEZ80 over Programming 1 marks does not show this behaviour with respect to the self-taught motivational bias. One explanation would be that the size of the sample is too small (there are few self-taught students in this group). It could also be a characteristic showing up only in some groups or it could depend on how strong other factors are. In any case, more experiments with greater samples are needed to better understand implications.

\subsection{Q3.c: Influence of self-reported likeness of programming}

Last confounding factor analysed in this study took into account how much did students report they liked programming. Better results are reasonable expectable in those students who like programming best. For these reason, our pre-DEZ80 survey asked students to report how much they enjoyed programming (see section 5.2). These question was only asked to those reporting previous programming experience, as it does not make sense otherwise.

To know if their previous likeness of programming had influenced their performance on Programming 1 marks, we calculated Pearson regression coefficients between their self-reported likeness and all their marks achieved (see table 7).

Table 7 Pearson coefficients between self-reported likeness of programming and Programming 1 marks. Students are considered by year (2017 or 2018) and by degree (Computer Engineering, CE or Multimedia, M). Tests are performed against marks obtained in each of the 3 Programming 1 exams ([Pr]actice-1 \& 2, and [The]ory) and against final marks (P1). $[N]$ : students meeting criteria.

\begin{tabular}{|l|r|r|r|r|r|}
\hline Group & $N$ & Pr-1 & Pr-2 & The & P1 \\
\hline \hline 2017-CE & 18 & 0.044 & 0.100 & 0.046 & 0.075 \\
2017-ME & 6 & $\underline{-0.744}$ & -0.347 & -0.750 & -0.636 \\
2018-CE & 19 & 0.092 & -0.012 & 0.067 & 0.122 \\
2018-ME & 13 & 0.342 & -0.046 & -0.319 & -0.084 \\
\hline
\end{tabular}

Surprisingly again, there seems to be no correlation between their likeness of programming and their achieved marks. There are only two feeble near significant correlations underlined (p-values 0.090 and 0.086 respectively). But even in these cases the Pearson correlation is negative, which means that those reporting less likeness had better results. Our best guess for this factor is the size of the sample, which is smaller for the group with negative correlation coefficient. Similarly, the two groups with higher sample count (2017-CE and 2018-CE) show values near 0, which supports the idea that their likeness had no influence as a confounding factor in this experiments.

Again, the fact that this confounding factor had not influenced results improves the likelihood that DEZ80 
had some real influence over Programming 1. However, similar to other analyses in this study, more evidence is required to support stronger conclusions, as the size of the sample in this study has very limited statistical significance.

\subsection{Limitations of results from this study}

After presenting results, due to restrictions and methodology, it is important to summarize their conditions and limitations:

- The sample consists only of students from the University of Alicante that already issued matriculation to Computer Engineering and Multimedia Degrees. Although they participated before starting their degrees, this represents a significant cognitive and interest bias.

- It was impossible to get a random sample from students because of management constraints. Therefore, the sample consisted of students that voluntarily asked to be part of the course.

- Participants had a narrow age range from 17 to 20 years, and were mainly male ( $78 \%$ male versus $22 \%$ female).

Therefore, presented results can only be considered a small piece of evidence conditioned to these circumstances. More studies and broader evidence are required to obtain statistically significant data and more generally applicable conclusions.

\section{Conclusions and further work}

This study started considering the problem of universal accessibility to the ability of computer programming. This is an increasingly demanded ability, core component of Computer Thinking, and in the future may be as important as reading is today. However, present approaches to teaching programming show great difficulties, and also some problems in the finally acquired mental models of students.

Present work considers an alternative approach, with a constructivist point of view, which begins exposing students to machine code and assembler programming. This approach is based on a sixteen hours blendedlearning course (abbreviated DEZ80), which has been designed from scratch, using game development as a main driver of contents. DEZ80 has been administered to a experimental group of first-years students at the University of Alicante, the week before their first term starts. This experiment has been repeated on academic years 2017/2018 and 2018/2019. Data gathered from students attending DEZ80 has been analysed and compared to students that did not attend, with respect to their marks in the Programming 1 subject. Additionally, potential confounding factors have been analysed and taken into account as part of the effects on results.

The main research questions in this study have been two: (1) Does attending DEZ80 influence Programming 1 marks?, and (2) Does performance in DEZ80 predict performance in Programming 1?. Results are not conclusive, but they show a potential relation on both questions. In case of this relation to actually exist, its influence seems to be small, difficult to statistically appreciate. This was expected because sixteen hours of non-mandatory course is a small educational intervention, and so its impact was also anticipated to be small, if any. Taking into account the size of the sample, results are to be considered positive because they leave open traces to the possibility of an actual influence. Therefore, more experiments and a much bigger data sample are required to clarify the existence of this relation and its strength.

Another interesting conclusion is with respect to the confounding factors considered: (1) Influence of previous programming experience, (2) Influence of selfteaching versus academic learning, and (3) Influence of likeness of programming. It is reasonable to think that these three factors can influence and even predict future performance in a subject like Programming 1. Contrary to expectations, results shown that none of them affected marks in a general sense. This has been a surprising finding of this study. However, for some of the student groups considered, factors (1) and (2) showed some influence. In the case of factor (1), that influence was found to strengthen the potential positive influence of DEZ80 on Programming 1 marks. On the contrary, factor (2) showed a strong significance that could explain results in one of the student groups, which diminished DEZ80's potential influence. Factor (3) did not show any statistical significance with any of the groups, which was again unexpected. As confounding factors are much more affected by the constrained size of their respective samples, more evidence is required to determine their general impact. Results suggest that self-teaching could be the strongest confounding factor, contrary to expectations.

Additionally, we need to insist on the existence of a bias due to the way students were selected for DEZ80. As they applied voluntarily, students had an expectable interest bias that could be an important confounding factor. However, this confounding factor could not be measured nor avoided. Therefore, it must be acknowledged and it is another reason to encourage the gathering of more and better evidence on this line of research. 


\section{Acknowledgements}

This research is partially supported by Cátedra Santander Universidad de Alicante de Transformación Digital.

\section{Compliance with ethical standards}

Conflict of interest. On behalf of all authors, the corresponding author states that there is no conflict of interest.

Ethical approval. Ethical approval was not required for this type of retrospective report.

Informed consent. All individual participants enrolled voluntarily in the courses from which data has been used for this report. They were informed in detail and informed consent was obtained from all of them.

\section{References}

1. Aho AV (2011) Ubiquity symposium: Computation and computational thinking. Ubiquity 2011(January):1, DOI 10.1145/1922681.1922682, URL https://doi.org/10.1145/1922681.1922682

2. ALEKSIĆ V, IVANOVIĆ M (2016) Introductory programming subject in european higher education. INFORMATICS IN EDUCATION 15(2):163182, DOI 10.15388/infedu.2016.09

3. Beidler J (1977) A place for assembler in structured programming. ACM SIGCSE Bulletin 9(1):108112, DOI 10.1145/382063.803370

4. Bennedsen J, Caspersen ME (2007) Failure rates in introductory programming. AcM SIGcSE Bulletin $39(2): 32-36$

5. Birch SA (2005) When knowledge is a curse. Current Directions in Psychological Science 14(1):2529, DOI 10.1111/j.0963-7214.2005.00328.x

6. Bloom BS, Engelhart MB, Furst EJ, Hill WH, Krathwohl DR (1956) Taxonomy of educational objectives. The classification of educational goals. Handbook 1: Cognitive domain. Longmans Green, New York

7. Cardellini L (2012) Chemistry: Why the Subject is Difficult? Educación Química 23:305 - 310

8. Coll RK, France B, Taylor I (2005) The role of models/and analogies in science education: implications from research. International Journal of Science Education 27(2):183-198, DOI 10.1080/ 0950069042000276712
9. Denning PJ, Tedre M (2019) Computational thinking. The MIT Press, Cambridge

10. Dolgopolovas V, Jevsikova T, Dagiene V (2017) From android games to coding in c-an approach to motivate novice engineering students to learn programming: A case study. Computer Applications in Engineering Education 26(1):75-90, DOI $10.1002 /$ cae. 21862

11. Esteves M, Fonseca B, Morgado L, Martins P (2010) Improving teaching and learning of computer programming through the use of the second life virtual world. British Journal of Educational Technology 42(4):624-637, DOI 10.1111/j.1467-8535.2010.01056.x, URL https://onlinelibrary.wiley.com/doi/ abs/10.1111/j.1467-8535.2010.01056.x, https://onlinelibrary.wiley.com/doi/pdf/ 10.1111/j.1467-8535.2010.01056.x

12. Freudenthal EA, Carter BA, Kautz FF, Ogrey AN (2008) Work in progress - combined introduction of $\mathrm{c}$ and assembly with a focus on reduction of high-level language constructs. In: 2008 38th Annual Frontiers in Education Conference, pp S2H3-S2H-4, DOI 10.1109/FIE.2008.4720618

13. Gallego-Durán FJ, Satorre Cuerda R, CompañRosique P, Villagrá-Arnedo CJ (2018) Explicando el bajo nivel de programación de los estudiantes. ReVisión 11(1), URL http://www. aenui. net/ojs/index . php?journal=revision\&page= article\&op=view\&path $\% 5 \mathrm{~B} \% 5 \mathrm{D}=409$

14. Gallego-Durán FJ, Villagrá-Arnedo CJ, SatorreCuerda R, Compañ-Rosique P, Llorens-Largo F (2018) Effects of low-level development on learning to program. In: Zaphiris P, Ioannou A (eds) Learning and Collaboration Technologies. Learning and Teaching, Springer International Publishing, Cham, vol 10925, pp 431-445, DOI 10.1007/ 978-3-319-91152-6_33

15. Gomes A, Mendes AJ (2007) Learning to program-difficulties and solutions. In: International Conference on Engineering Education-ICEE, vol 2007, URL https: //www.researchgate.net/profile/Anabela_ Gomes2/publication/228328491_Learning_ to_program_-_difficulties_and_solutions/ links/02e7e52389017b9984000000.pdf

16. Greca IM, Moreira MA (2000) Mental models, conceptual models, and modelling. International Journal of Science Education 22(1):1-11, DOI 10.1080/095006900289976, URL https://periodicos.ufsc.br/index.php/ fisica/article/viewFile/6895/14041 
17. Greca IM, Moreira MA (2001) Mental, physical, and mathematical models in the teaching and learning of physics. Science Education 86(1):106121, DOI 10.1002/sce.10013

18. Guzdial M (2015) Learner-centered design of computing education: Research on computing for everyone. Synthesis Lectures on HumanCentered Informatics 8(6):1-165, DOI 10.2200/ S00684ED1V01Y201511HCI033

19. Hooshyar D, Ahmad RB, Yousefi M, Fathi M, Horng SJ, Lim H (2016) Applying an online game-based formative assessment in a flowchartbased intelligent tutoring system for improving problem-solving skills. Computers \& Education 94:18-36, DOI 10.1016/j.compedu.2015. 10.013, URL http://www.sciencedirect.com/ science/article/pii/S0360131515300622

20. Ivanović M, Budimac Z, Radovanović M, Savić M (2015) Does the choice of the first programming language influence students' grades? DOI 10.1145/ 2812428.2812448

21. Ivanovića M, Budimac Z (2013) First programming language - never-ending story. In: 11th International Conference of Numerical Analysis and Applied Mathematics 2013, ICNAAM 2013, AIP Conference Proceedings, vol 1558, pp 353-356, DOI $10.1063 / 1.4825496$

22. Jenkins $\mathrm{T}$ (2002) On the difficulty of learning to program. In: Proceedings of the 3rd Annual Conference of the LTSN Centre for Information and Computer Sciences, Citeseer, vol 4, pp 53-58

23. Jiau HC, Chen JC, Ssu KF (2009) Enhancing selfmotivation in learning programming using gamebased simulation and metrics. IEEE Transactions on Education 52(4):555-562, DOI 10.1109/te.2008. 2010983

24. Johnson-Laird PN (1983) Mental Models. Cognitive science series, Cambridge University Press, URL https://books.google.es/books?id= -XU6AAAAIAAJ

25. Joint Task Group on Computing Curricula (2016) Computer Engineering Curricula 2016: Curriculum Guidelines for Undergraduate Degree Programs in Computer Engineering. ACM, New York, NY, USA, URL http: //www . acm.org/binaries/content/ assets/education/ce2016-final-report.pdf

26. Justi R, van Driel J (2006) The use of the interconnected model of teacher professional growth for understanding the development of science teachers' knowledge on models and modelling. Teaching and Teacher Education 22(4):437 - 450, DOI 10.1016/ j.tate.2005.11.011, URL //www.sciencedirect.
com/science/article/pii/S0742051X05001514

27. Kelleher C, Pausch R (2005) Lowering the barriers to programming. ACM Computing Surveys 37(2):83-137, DOI 10.1145/1089733.1089734

28. Lahtinen E, Ala-Mutka K, Järvinen HM (2005) A study of the difficulties of novice programmers. SIGCSE Bull 37(3):14-18, DOI 10.1145/ 1151954.1067453, URL http://doi.acm.org/10. $1145 / 1151954.1067453$

29. Li Y (2016) Teaching programming based on computational thinking. In: 2016 IEEE Frontiers in Education Conference (FIE), Amer Soc Engn Educ Educ Res Methods Div; Inst Elect \& Elect Engineers Comp Soc; Inst Elect \& Elect Engineers Educ Soc; IEEE Comp Soc; Erie; Inst Elect \& Elect Engineers, IEEE, 345 E 47TH ST, NEW YORK, NY 10017 USA, Frontiers in Education Conference, DOI 10.1109/fie.2016.7757408, iEEE Frontiers in Education Conference (FIE), Gannon Univ, Erie, PA, OCT 12-15, 2016

30. Madrid MJ, Leon-Mantero C, Maz-Machado A (2015) Assessment of the attitudes towards mathematics of the students for teacher of primary education. OALib 02(11):1-8, DOI 10.4236/oalib. 1101936, URL http://www.oalib.com/paper/ $\mathrm{pdf} / 3150582$

31. Mannila L, Dagiene V, Demo B, Grgurina N, Mirolo C, Rolandsson L, Settle A (2014) Computational thinking in k-9 education DOI 10.1145/ 2713609.2713610

32. Murphy E, Crick T, Davenport JH (2017) An analysis of introductory programming courses at uk universities URL https://repository.cardiffmet. ac.uk/bitstream/handle/10369/8417/1609. $06622 \mathrm{v} 2 \cdot \mathrm{pdf}$ ? sequence $=1 \&$ is $\mathrm{s}$ llowed $=y$

33. Norman DA (1983) Some observations on mental models. Mental models 7(112):7-14

34. Ousterhout J (1998) Scripting: higher level programming for the 21st century. Computer 31(3):2330, DOI 10.1109/2.660187

35. Patt Y, Patel S (2020) Introduction to Computing Systems: From Bits \& Gates to $\mathrm{C} / \mathrm{C}++\&$ Beyond, third edition edn. McGraw-Hill, URL https : //Iccn.loc.gov/2018050089

36. Robins A, Rountree J, Rountree N (2003) Learning and teaching programming: A review and discussion. Computer science education 13(2):137172, URL http://www.tandfonline.com/doi/ abs/10.1076/csed.13.2.137.14200

37. Roche J (1995) Why is physics so difficult? Physics World 8(6):17

38. Ryan RM, Deci EL (2000) Self-determination theory and the facilitation of intrinsic motivation, so- 
cial development, and well-being. American Psychologist 55(1):68-78

39. Schell J (2008) The Art of Game Design: A Book of Lenses. Morgan Kaufmann Publishers Inc., San Francisco, CA, USA

40. Scott MJ, Counsell S, Lauria S, Swift S, Tucker A, Shepperd M, Ghinea G (2015) Enhancing practice and achievement in introductory programming with a robot olympics. IEEE Transactions on Education 58(4):249-254, DOI 10.1109/te.2014. 2382567

41. Serrano-Cámara LM, Paredes-Velasco M, Alcover CM, Velazquez-Iturbide JÁ (2014) An evaluation of students' motivation in computersupported collaborative learning of programming concepts. Computers in Human Behavior 31:499-508, DOI 10.1016/j.chb.2013.04.030, URL http://www.sciencedirect.com/science/ article/pii/S0747563213001428

42. Singh RG, Scholliers C (2019) WARDuino: a dynamic WebAssembly virtual machine for programming microcontrollers DOI 10.1145/3357390. 3361029

43. Sittiyuno S, Chaipah K (2019) ARCode: Augmented reality application for learning elementary computer programming. In: 2019 16th International Joint Conference on Computer Science and Software Engineering (JCSSE), IEEE, pp 32-37, DOI $10.1109 /$ jcsse.2019.8864173

44. Steffe L (1995) Constructivism in Education. Lawrence Erlbaum, Hillsdale, N.J

45. Swigger KM, Wallace LF (1988) A discussion of past programming errors and their effect on learning assembly language 8(5):395399, DOI 10.1016/0164-1212(88)90030-1, URL http://www.sciencedirect.com/science/ article/pii/0164121288900301

46. Tedre M, Denning PJ (2016) The long quest for computational thinking DOI 10.1145/2999541. 2999542

47. Thomas L, Ratcliffe M, Thomasson B (2004) Can object (instance) diagrams help first year students understand program behaviour? In: Diagrammatic Representation and Inference, Springer, Berlin, Heidelberg, Lecture Notes in Computer Science, pp 368-371, DOI 10.1007/978-3-540-25931-2_41, URL https://link.springer.com/chapter/10. 1007/978-3-540-25931-2_41

48. Özcan Özyurt, Özyurt H (2016) Using facebook to enhance learning experiences of students in computer programming at introduction to programming and algorithm course. Computer Applications in Engineering Education
24(4):546-554, DOI $10.1002 /$ cae.21730, URL https://onlinelibrary.wiley.com/doi/abs/ 10.1002/cae.21730, https://onlinelibrary. wiley.com/doi/pdf/10.1002/cae.21730 